\title{
Investigation of dominant traveling 10-day wave components using long-term MERRA-2 database
}

\author{
Chunming Huang ${ }^{1,2^{*}}$, Wei Li ${ }^{1}$, Shaodong Zhang ${ }^{1,2^{*}}$, Gang Chen ${ }^{1,2}$, Kaiming Huang ${ }^{1,2}$ and Yun Gong ${ }^{1,2}$
}

\begin{abstract}
The eastward- and westward-traveling 10-day waves with zonal wavenumbers up to 6 from surface to the middle mesosphere during the recent 12 years from 2007 to 2018 are deduced from MERRA-2 data. On the basis of climatology study, the westward-propagating wave with zonal wave number 1 (W1) and eastward-propagating waves with zonal wave numbers 1 (E1) and 2 (E2) are identified as the dominant traveling ones. They are all active at mid- and high-latitudes above the troposphere and display notable month-to-month variations. The W1 and E2 waves are strong in the NH from December to March and in the SH from June to October, respectively, while the E1 wave is active in the SH from August to October and also in the NH from December to February. Further case study on E1 and E2 waves shows that their latitude-altitude structures are dependent on the transmission condition of the background atmosphere. The presence of these two waves in the stratosphere and mesosphere might have originated from the downward-propagating wave excited in the mesosphere by the mean flow instability, the upward-propagating wave from the troposphere, and/or in situ excited wave in the stratosphere. The two eastward waves can exert strong zonal forcing on the mean flow in the stratosphere and mesosphere in specific periods. Compared with E2 wave, the dramatic forcing from the E1 waves is located in the poleward regions.
\end{abstract}

Keywords: 10-day waves, Travelling planetary wave, Middle atmosphere

\section{Introduction}

Planetary waves (PWs) are oscillations of very predominantly tropospheric origin with typical periods of about 2-30 days in the troposphere and lower stratosphere (TLS), the mesosphere and lower thermosphere (MLT), as well as the ionosphere (Vincent 1990; Forbes et al. 1995; Hirooka 2000; Riggin et al. 2006; McDonald et al. 2011; Yue et al. 2012; Moudden and Forbes 2014; Forbes and Zhang 2015; Pancheva et al. 2016). PWs can be classified either as free modes or as forced waves. From solutions of Laplace's tidal equation, a series of classical normal modes can be obtained (Salby 1984). The Rossby

\footnotetext{
*Correspondence: huangcm@whu.edu.cn; zsd@whu.edu.cn

${ }^{1}$ School of Electronic Information, Wuhan University, Wuhan, Hubei,

China

Full list of author information is available at the end of the article
}

normal modes propagate westward with periods (zonal wavenumbers) near $2(s=3), 5(s=1), 10(s=1)$, and $16(s=1)$ days, are often referred to, respectively, as the quasi-2-day wave, quasi-5-day wave, quasi-10-day wave, and quasi-16-day wave. These normal modes have been extensively investigated during recent decades (Salby 1981, 1984; Hirooka and Hirota 1985; Hirooka 1986, 2000; Madden 2007; Sassi et al. 2012). Among these modes, the quasi-10-day wave attracts less attention and it is studied inadequately. The investigations specifically for the quasi-10-day wave are relatively rare. Forbes and Zhang (2015) provided a comprehensive perspective on the westward-propagating quasi-10-day wave with zonal wavenumber 1 by using temperature measurements from the Sounding of the Atmosphere using Broadband Emission Radiometry (SABER) and found that it conforms reasonably well with theoretical expectations for a 
normal mode, at least below $80 \mathrm{~km}$ and its mean period is 9.8 day with a standard deviation of about 0.4 day. They also found that the wave is strong during winter months and weak during summer months. Limited by the employed data, they only displayed the quasi-10day wave in temperature between 20 and $100 \mathrm{~km}$ and $50^{\circ} \mathrm{S}-50^{\circ} \mathrm{N}$ latitude. Hirooka (2000) did provide some insight into the normal mode of the quasi-10-day wave in the stratosphere and lower mesosphere for some limited time periods by UARS/ISAMS observations. It was found that the wave structure is easily influenced in the mesosphere by nonuniform and strong background zonal winds and the vertical growth of wave amplitudes is prohibited in the mesosphere even without critical regions.

Except the normal mode of the quasi-10-day wave, the actual atmospheric wavefield associated with a period of about 10 days was also found to be made of a number of eastward-propagating wave components especially in the winter Southern Hemisphere stratosphere (Hartmann 1979, 1983; Mechoso and Hartmann 1982; Palo et al. 2005). The eastward-traveling waves of zonal wavenumber 2 with a period of about 1-2 weeks might be baroclinically unstable modes (Hartmann 1979), and the plausible mechanisms associated with negative potential vorticity gradient of the stratospheric westerly jet were discussed (Hartmann 1983). The eastwardtraveling planetary waves of wavenumbers 1 and 2 in the Southern Hemisphere stratosphere tended to be incoherent with their counterparts in the troposphere, and zonal flow instability in the stratosphere could explain this behavior (Mechoso and Hartmann 1982). The eastwardtraveling 10-day waves with zonal wavenumbers 1 and 2 , appearing from the stratosphere to the thermosphere during the Southern Hemisphere pre-stratwarm period, were also considered due to zonal flow instability relating to the strong middle atmosphere jet (Palo et al. 2005). Therefore, the large-scale wave with a period of about 10 days observed in the middle atmosphere is a mixture of normal mode and forced waves. That is to say, the westward- and eastward-traveling 10-day waves coexist in the middle atmosphere. The global structure and seasonal variability of the eastward-and westward-traveling quasi-2-day and 6-day waves have been presented in previous research (Pancheva et al. 2016, 2018). However, little study on the counterparts of the 10-day wave has been done, especially in wind fields, which is exactly the main objective of this paper.

PW characteristics in the atmosphere have been examined by using various observations. Radiosonde observations have been extensively used to explore PW characteristics in TLS (Huang et al. 2009). The mesosphere-stratosphere-troposphere (MST), mediumfrequency and Meteor radar measurements have also been utilized effectively to study the seasonal and altitudinal variability of local PWs in the TLS (Huang et al. 2017, 2015; Williams and Avery 1992), MLT (Luo et al. 2000), and mesopause (Gong et al. 2018), respectively. However, the radiosonde, MST, medium-frequency and Meteor radar stations are all very sparse and observation data from these sources are still insufficient. Highresolution satellite observations have contributed a lot in the investigation of global characteristics of PWs since they are capable of demonstrating the three-dimensional propagation scenarios of PWs. However, most satellites are capable of providing reliable data, as it is in SABER, only above the lower stratosphere. Moreover, such satellite observations can only offer relatively limited physical quantities like temperature. The Modern-Era Retrospective Analysis for Research and Applications version 2 (MERRA-2) provides the latest atmospheric reanalysis data from the modern satellite era (Gelaro et al. 2017). A variety of observations are assimilated in MERRA-2 so that it can provide relatively complete physical quantities such as horizontal wind and temperature in a large altitude range from surface to the mesosphere. The MERRA-2 product of "inst6_3d_ana_Nv" is used as the primary dataset in this study to explore global characteristics of the traveling 10-day waves.

Classical PW studies indicate that the atmospheric background state affects planetary wave propagation by altering the refractive index (Charney and Drazin 1961), hence PW amplitude and phase strongly depend on the background wind conditions (Grieger and Schmitz 1982). On the other hand, accompanying with propagation and dissipation, PWIs can exert force on and deposit momentum into the background atmosphere, and in turn, affect significantly the atmospheric dynamical and thermal structures. PWs are believed to be forced by a variety of mechanisms. The troposphere is the predominant source region for PWs. They are forced by orography and patterns of diabatic heating arising from the distribution of land and sea (quasi-stationary PWs) or by irregular thermal or mechanical forcing (traveling PWs). From the stratosphere up to the mesosphere, PWs might be a result of upward propagation of the tropospheric PWs, or be excited in situ by zonally asymmetric gravity wave sources, the barotropic and baroclinic instability, the dissipation and breaking of gravity waves filtered by background winds, etc. (Meyer and Forbes 1997; Holton 1984; Smith 1996; Osprey and Lawrence 2001; Chun and Kim 2008). However, there is still a lack of relevant research on the excitation of the eastward-traveling 10-day waves from surface to the middle mesosphere and their interactions with the mean flow.

In this paper, we report global characteristics of 10-day waves with various zonal wavenumbers presented in the 
MERRA-2 data during the recent 12 years from 2007 to 2018. We firstly identify the dominant eastward- and westward-traveling modes of the 10-day waves, and then present their global structures and month-to-month variability. Afterwards, we focus on the dominant eastwardpropagating ones, and explore the dependence of their spatial structures on the atmospheric transmission conditions as well as their likely sources by case study.

\section{Data and method of analysis}

MERRA is a state-of-the-art reanalysis data product that provides atmospheric fields, as well as global estimates of soil moisture, latent heat flux, snow, and runoff for 1979-2016 (Rienecker et al. 2011).Version 2 of MERRA(MERRA-2) is introduced to replace the original MERRA dataset because of the advances made in the assimilation system beginning in 1980 (Gelaro et al. 2017). MERRA-2 updates the Global Statistical Interpolation (GSI) analysis scheme and the Goddard Earth Observing System (GEOS) model, and combines model fields with multiple observations distributed irregularly in space and time into a spatially complete gridded meteorological dataset. The scientific quality of MERRA and MERRA-2 products has been evaluated in previous studies by comparing with reference datasets. Rienecker et al. (2011) found that the differences between January 2004 radiosonde temperature observations and the final analysis from MERRA for the globe were relatively small (less than $0.2 \mathrm{~K}$ ) at most pressure levels. Gelaro et al. (2017) provided global background departure statistics for radiosonde temperatures for MERRA-2 in the troposphere and stratosphere, and found the amplitudes of the departure values were basically smaller than $1 \mathrm{~K}$. Compared with MERRA, MERRA-2 improved representations of the stratosphere, but included an increased warm bias reaching maximum amplitude of slightly greater than $0.5 \mathrm{~K}$ in the upper troposphere. The product "inst6_3d_ana_Nv" from MERRA-2 is analyzed fields at the four synoptic times (00 GMT, 06 GMT, 12 GMT, and 18 GMT) at 72 nominal pressure levels varying from $985 \mathrm{hPa}$ to $0.01 \mathrm{hPa}$ with the native resolution of 0.625 -degree longitude by 0.5 -degree latitude. It covers longitude from $180.0^{\circ} \mathrm{W}$ to $179.375^{\circ} \mathrm{E}$ and latitude from $90.0^{\circ} \mathrm{S}$ to $90.0^{\circ} \mathrm{N}$. In this study, physical quantities of eastward wind component $(\mathrm{U})$, northward wind component $(\mathrm{V})$, and air temperature $(\mathrm{T})$ are considered for the analysis.

We choose a 30-day fitting window centered on the middle date of each month to get the amplitudes and phases of the 10-day waves in each month. Within each window, monthly average and the linear trend are removed from the raw data at any given height and latitude as the background component. Then harmonic fits are performed on the residuals with respect to 13 different modes of 10-day waves (zonal wavenumbers varying from -6 to 6 ) for periods varying from 8.0 to 12.0 days in increments of 0.25 days. Since the 10-day wave is quasiperiodic, here we classify it using a period band from 8 to 12 day (Forbes and Zhang 2015; Huang et al. 2015) rather than a single period. The formula used for the fit is as follows:

$$
f(\lambda, t)=A \cos \left(\frac{2 \pi}{T} t-\frac{2 \pi}{360} s \lambda-\phi\right)
$$

where $t$ is the time in days; $\lambda$ is the longitude in degrees; $A, T, s$ and $\phi$ are, respectively, the amplitude, period, zonal wavenumber and phase of the 10-day waves. The positive zonal wavenumbers represent eastward propagation while negatives are westward. For a certain mode of 10-day waves, its amplitude at any given height and latitude in each month corresponds to the one fit among these periods that has the largest amplitude.

In order to check the reliability of the 10-day wave results deduced from MERRA-2 data, we present the latitude versus altitude structures of the 10-day wave amplitude in temperature at latitudes between $50^{\circ} \mathrm{S}$ and $50^{\circ}$ $\mathrm{N}$ in Fig. 1, and provide detailed comparisons with the results from Forbes and Zhang (2015). We compute the confidence level for each harmonic fit, and find that the confidence level is greater than $95 \%$ when the zonal and meridional wind amplitudes are larger than $2.5 \mathrm{~ms}^{-1}$ or the temperature amplitude is larger than $1 \mathrm{~K}$. For convenient comparison, the multiyear average (2002-2013) temperature amplitude of the westward-propagating 10-day wave with zonal wavenumber 1 is calculated. In general, our results are very consistent with those from Forbes and Zhang (2015). The W1 10-day wave is strong at mid-latitudes during winter and around the equinoxes; larger amplitudes favor the spring hemisphere around the equinoxes; there are two maximums at about $45 \mathrm{~km}$ and $70 \mathrm{~km}$ in the winter and spring hemispheres, respectively. In this figure, we also display the counterparts of the eastward-propagating 10-day wave with zonal wavenumbers 1 and 2, i.e., E1 and E2 waves, which are identified as the dominant traveling ones together with the W1 wave in the following section. The E1 wave is active and has comparable amplitudes at mid-latitudes during the $\mathrm{NH}$ winter and the SH spring. The E2 wave is very conspicuous at mid-latitudes during the $\mathrm{SH}$ spring. Both waves are very weak in the summer and autumn hemispheres.

\section{The dominant 10-day waves and their characteristics}

For revealing statistical characteristics of 10-day waves, we deduce the amplitudes of the different modes with zonal wavenumbers varying from -6 to 6 in the recent 


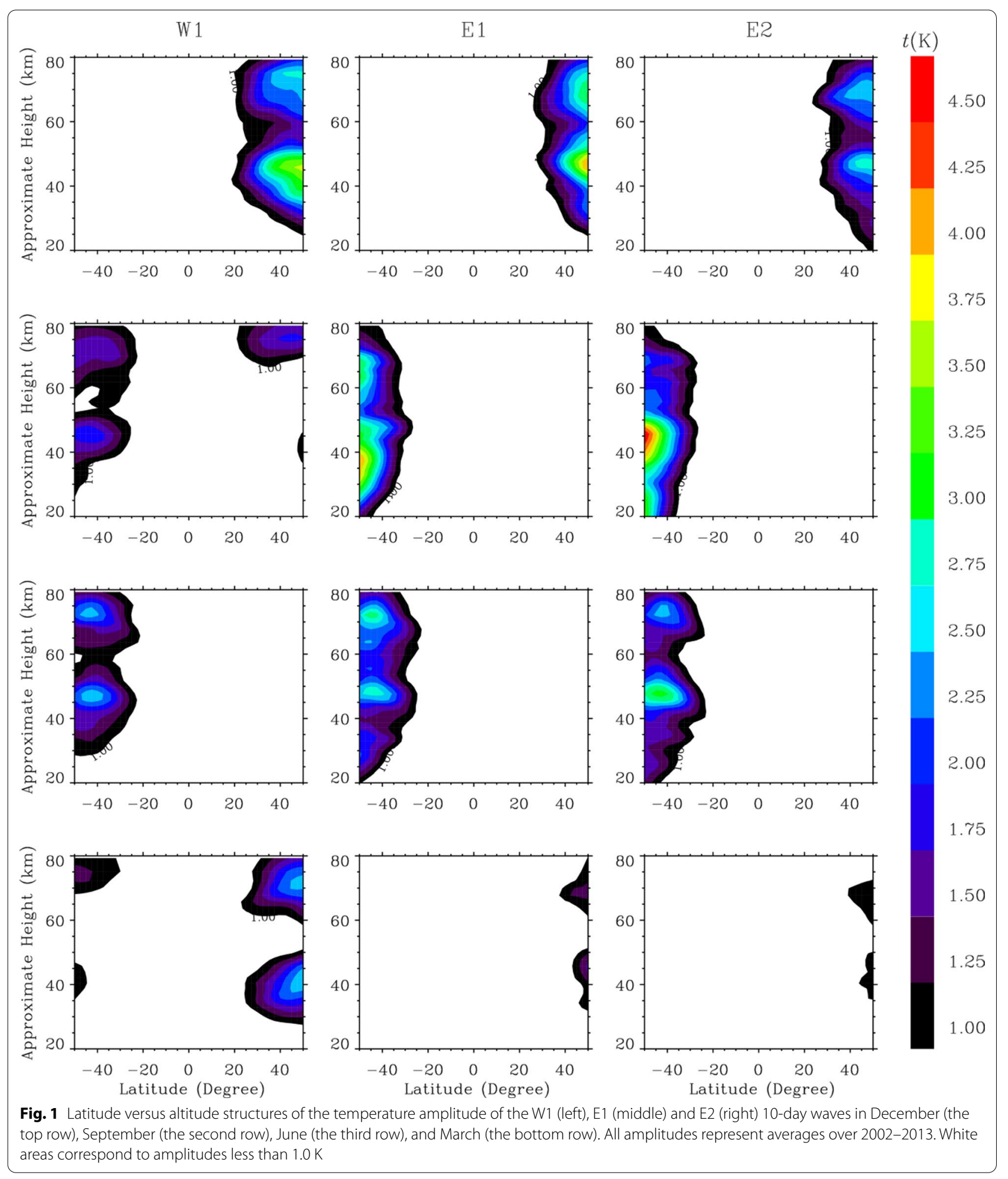

12 years from 2007 to 2018 from the MERRA-2 data as mentioned above. A fitting amplitude is obtained for each mode at any given height and latitude for each month during the period of 2007-2018 (144 months in total). We check all the fitting amplitudes for each mode, and the significance of these 13 waves is evaluated according to their large amplitude occurrence rate. The term "large amplitude" is used for the zonal and 
meridional wind amplitudes exceeding $10.0 \mathrm{~ms}^{-1}$ and the temperature amplitude larger than $5.0 \mathrm{~K}$. The large amplitude occurrence rate is defined as the number of the large amplitudes divided by the total number of the fitting amplitudes. The "large amplitude" criteria are chosen according to the observational and fitting 10-day wave amplitudes. UARS/ISAMS observations estimated that the 10-day wave with $\mathrm{s}=-1$ could be larger than $10-20 \mathrm{~ms}^{-1}$ in the mesosphere (Hirooka 2000). SABER temperature observations showed that the 10-day wave components with $s=1$ and $s=2$ extended from the lower stratosphere to the lower thermosphere with little amplitude attenuation and the peak amplitudes could exceed $10 \mathrm{~K}$ or even $20 \mathrm{~K}$ (Palo et al. 2005). In our fitting results, the maximum zonal wind, meridional wind and temperature amplitudes are $30.7 \mathrm{~ms}^{-1}, 31.1 \mathrm{~ms}^{-1}$ and $10.2 \mathrm{~K}$, respectively. The fitted zonal and meridional wind amplitudes larger than $10 \mathrm{~ms}^{-1}$ and the fitted temperature amplitude larger than $5 \mathrm{~K}$ are with very high confidence level, and there are quite a number of fitted amplitudes that exceed these values.

The large amplitude occurrence rates of the 13 waves for the zonal wind, meridional wind, and temperature are presented in the top row of Fig. 2. It is clear that large occurrence rates are concentrated in the zonal wavenumbers varying from -1 to 2 . It can be concluded that the dominant 10-day components are the westward-propagating wave with $s=-1$, the eastward-propagating waves with $s=1,2$, and the zonally symmetric oscillation with $s=0$. The large amplitude occurrence rate for the $s=0$ component for the meridional wind is zero, which is regarded as a result of the geostrophic approximation (Pancheva et al. 2007, 2008). Since the earlier studies (Pancheva et al. 2007, 2008) conducted a detailed research on the zonally symmetric oscillations, the three traveling waves will be focused in this study. For simplicity, the waves with $s=-1, s=1$, and $s=2$ will be referred as W1, E1, and E2 waves, respectively.

The distributions of large amplitude occurrence rates over amplitude, latitude, height, and month for W1, $\mathrm{E} 1$, and E2 waves are provided in the last four rows in Fig. 2. Observing the first two rows in Fig. 2, it is clear that although W1 wave is one of the dominant waves, it seems not the one with the greatest significance. Besides, the most dominant one for the zonal wind and temperature is E1 wave while it is E2 wave for the meridional wind. For all the three quantities, E1 wave has the largest amplitudes.

The distribution of large amplitude occurrence rates over latitude shows good hemispherical symmetry for E1 wave while evident hemispherical asymmetry for W1 and E2 waves. For W1 wave, the larger amplitudes take place more often in the northern hemisphere $(\mathrm{NH})$ when compared to the southern hemisphere $(\mathrm{SH})$. They are centered at $\sim 30^{\circ} \mathrm{N}$ and around the northern polar region in the zonal wind; around the northern polar region in the meridional wind; and at $\sim 65^{\circ} \mathrm{N}$ in the temperature. For E1 wave, large amplitudes are observed in both hemispheres. They are concentrated at $\sim 45^{\circ}$ and around the polar regions in the zonal wind; around the polar regions in the meridional wind; and at $\sim 60^{\circ}$ in the temperature. For E2 wave, large amplitudes occur mainly in the $\mathrm{SH}$. They are centered at $\sim 60^{\circ} \mathrm{S}$ in the meridional wind and temperature while at $\sim 35^{\circ} \mathrm{S}$ and $\sim 70^{\circ} \mathrm{S}$ in the zonal wind. Large amplitude occurrence rate at the equator region is negligible except for W1 wave in the zonal wind.

In terms of the height distributions of large amplitude occurrence rates, it can be observed that most of the large amplitudes appear above the troposphere except for the E2 wave in temperature. In the zonal and meridional winds, large amplitudes for W1, E1, and E2 waves are centered at $\sim 58, \sim 50$, and $\sim 40 \mathrm{~km}$, respectively. In the temperature, two local centers for W1 $(\sim 45$ and $\sim 75 \mathrm{~km})$ and E1 $(\sim 35$ and $\sim 65 \mathrm{~km})$ waves, while three for E2 $(\sim 20, \sim 45$ and $\sim 70 \mathrm{~km})$ wave, are observed.

The distribution of large amplitude occurrence rates over month is divided into the $\mathrm{NH}$ and the $\mathrm{SH}$. W1 wave is active in the $\mathrm{NH}$ from December to March in all the three physical quantities, and in the $\mathrm{SH}$ from June to August only in the zonal wind. E2 wave is strong in the $\mathrm{SH}$ in winter and spring months, and in the $\mathrm{NH}$ only in January. E1 wave is active in both hemispheres in winter and particularly intensive in the SH in September. The 10-day waves are very weak during the summer months for all the three waves.

Above statistical results show that at $\sim 44 \mathrm{~km}$, all the three dominant 10-day waves have prominent amplitudes in all components (the zonal wind, the meridional wind and temperature). Next, we would provide the multiyear average (2007-2018) zonal wind, meridional wind, and temperature amplitudes of the W1, E1 and E2 10-day waves at $\sim 44 \mathrm{~km}$ in each month in Fig. 3. It can be seen that all the three waves are salient at mid- and high-latitudes and exhibit notable month-to-month variations. The strongest W1 and E2 waves occur in January in the $\mathrm{NH}$ and September in the SH, respectively. For W1 wave, the maximum zonal and meridional wind amplitudes are, respectively, 11.1 and $11.3 \mathrm{~ms}^{-1}$, both located in the polar region. The maximum temperature amplitude is $3.6 \mathrm{~K}$ at $50^{\circ} \mathrm{N}$. For E2 wave, the maximum zonal and meridional wind amplitudes are, respectively, $9.1 \mathrm{~ms}^{-1}$ at $75^{\circ} \mathrm{S}$ and $14.1 \mathrm{~ms}^{-1}$ at $65^{\circ} \mathrm{S}$. The maximum temperature amplitude is $5.1 \mathrm{~K}$ at $55^{\circ} \mathrm{S}$. The E1 wave is very conspicuous both in January in the NH and September in the SH. The maximum wind and temperature amplitudes are comparable in both hemispheres, exceeding $12 \mathrm{~ms}^{-1}$ and $3.5 \mathrm{~K}$, 

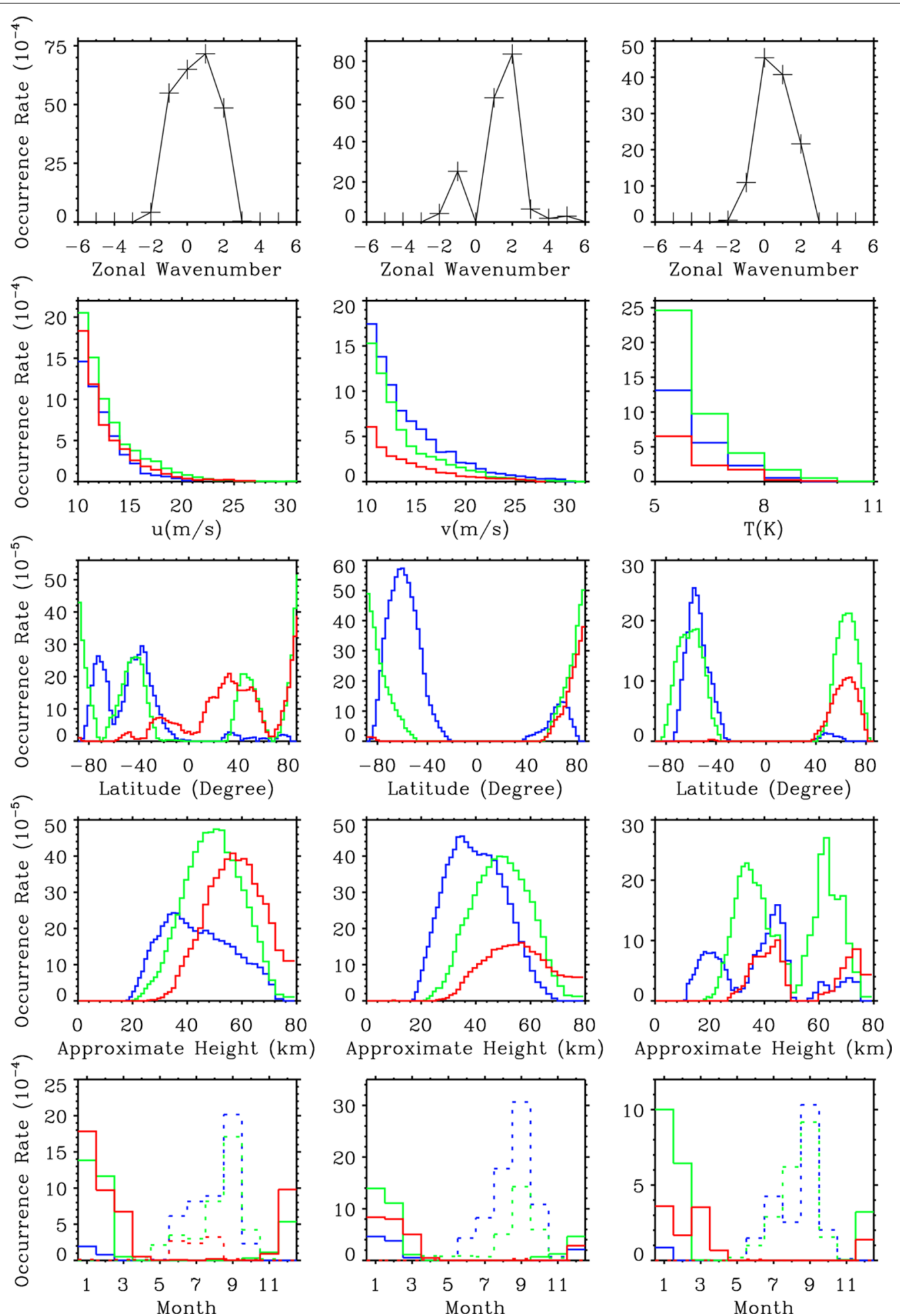

Fig. 2 Large amplitude occurrence rates for the 10-day waves with different zonal wavenumbers (the top row) and their distributions over amplitude (the second row), latitude (the third row), height (the fourth row), and month (the bottom row) in the zonal wind (left), meridional wind (middle) and temperature (right) for the dominant traveling waves. The red/green/blue histograms are for W1/E1/E2 wave in the last four rows, and the solid/dotted histograms in the bottom row are for the Northern/Southern Hemisphere 


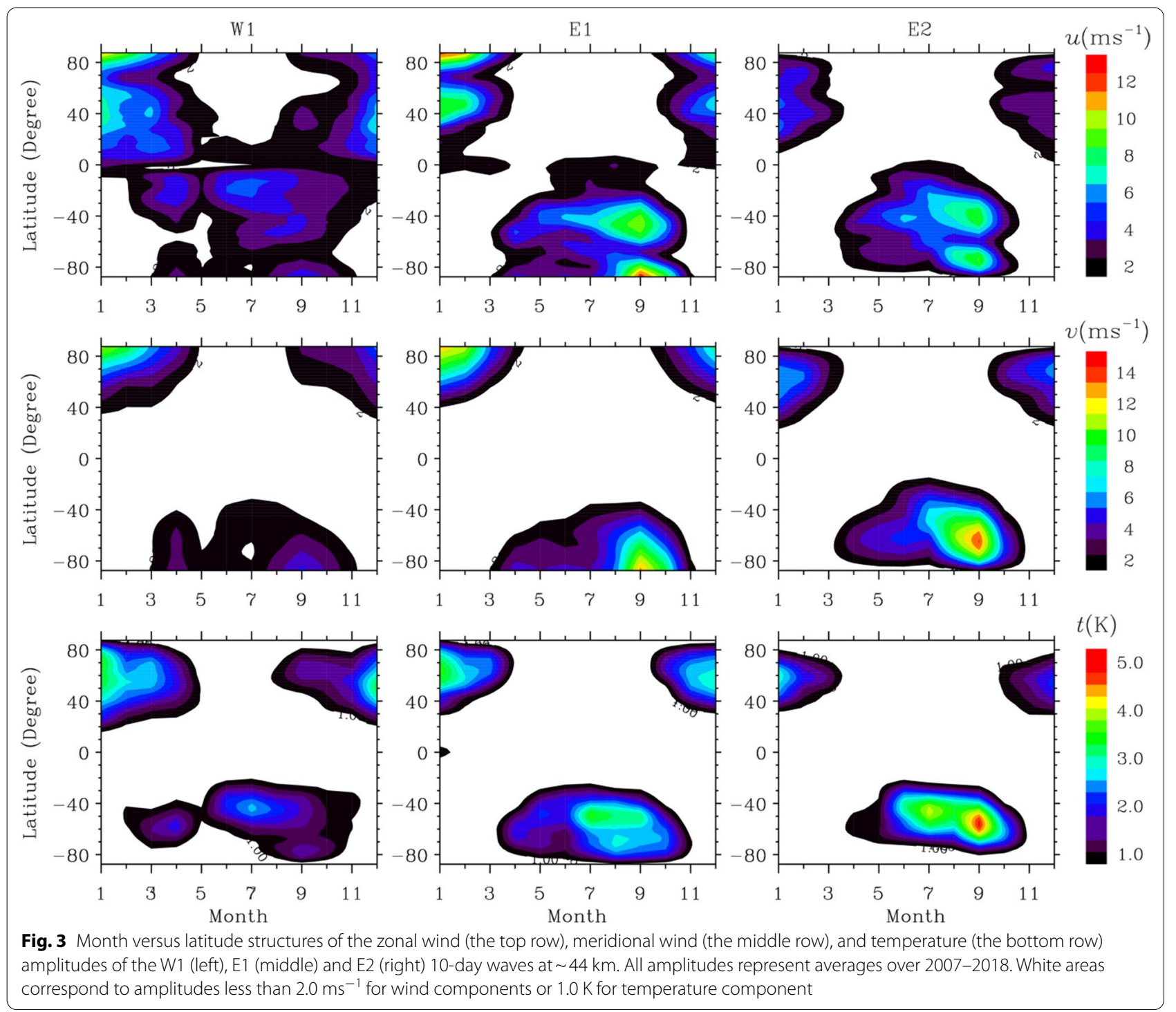

respectively. The zonal wind amplitudes for all the three waves have a secondary maximum around $\pm 42.5^{\circ}$. The global characteristics of the W1, E1, and E2 10-day waves revealed by this figure conform well to those from the above statistical analyses.

\section{Case study for the eastward-traveling 10-day waves}

It is well known that there is a complicated relationship between the 10-day waves and the atmospheric background. The atmospheric background can control wave propagation and excite waves in situ by the barotropic and baroclinic instability. On the other hand, the 10-day wave can alter the atmospheric background by exerting force and depositing momentum. Therefore, we would like to carefully explore the correlation between the eastward-propagating 10-day waves and the mean flow by case study. Since the 10-day waves have dramatic variations during a month, smaller time periods like 20 days are selected to study the propagation, excitation and momentum deposition of the transient 10-day waves. Harmonic fits introduced in "Data and method of analysis" section are performed again, but this time it is applied to the 20-day window. The window is moved through each month with steps of 1 day. In order to provide convincing case study for the E1 and E2 waves, we select the windows when only one wave has very significant amplitudes and the others are weak. We find that the windows of September 11-30, and June 2-21 meet the requirements. Figure 4 displays 

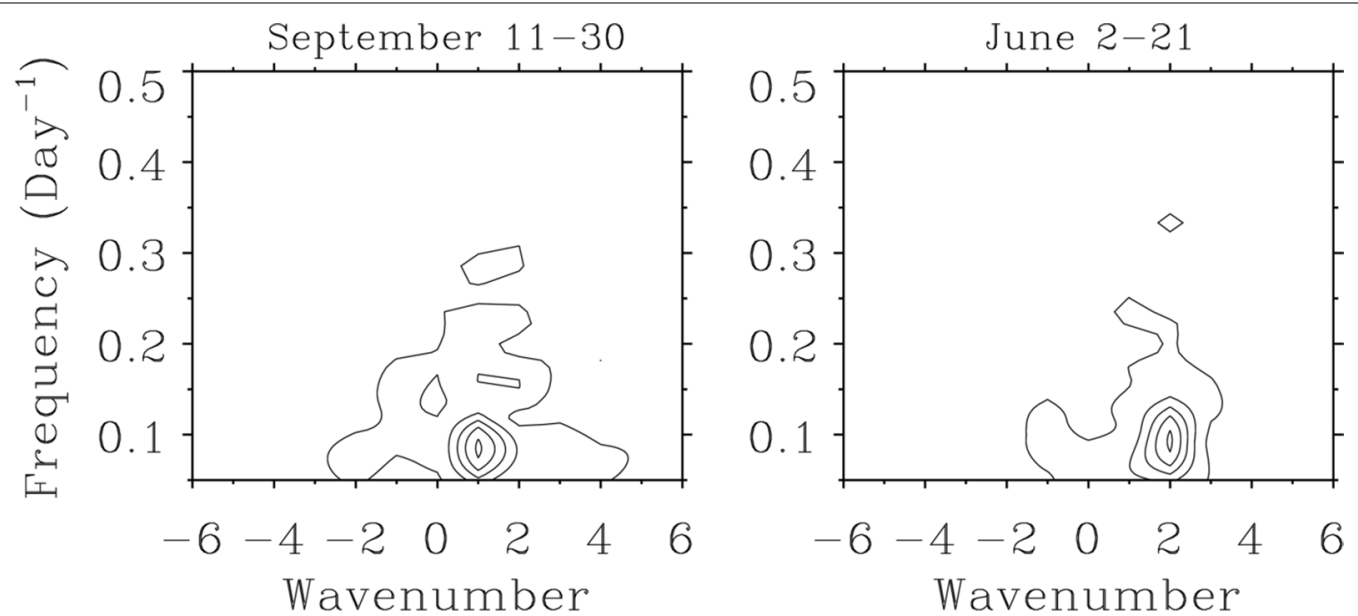

Fig. 4 The normalized frequency-wavenumber spectra of the zonal wind disturbance at $47.5^{\circ} \mathrm{S}$ and $\sim 42 \mathrm{~km}$ in September $11-30$ (left) and at $52.5^{\circ} \mathrm{S}$ and $\sim 58 \mathrm{~km}$ in June 2-21 (right). The minimum and interval of the contours are 0.15 and 0.2 , respectively

the normalized frequency-wavenumber spectra of the zonal wind disturbance at $47.5^{\circ} \mathrm{S}$ and $\sim 42 \mathrm{~km}$ during September $11-30$ and at $52.5^{\circ} \mathrm{S}$ and $\sim 58 \mathrm{~km}$ during June 2-21. It is clear that the E1 wave is overwhelming during September 11-30 while the E2 wave is predominant during June $2-21$. Hence wave events during these two windows are chosen as representative cases for E1 and E2 waves, respectively. Potential vorticity gradient, refractive index squared, Eliassen-Palm flux and its divergence during September 11-30 and June 2-21 are examined in order to explain the latitude-height structures and their local excitation. The calculation results corresponding to E1 and E2 waves are provided in the first and second columns in Fig. 5, respectively.

The following formula is employed to calculate the basic northward potential vorticity gradient (Andrews 1987; Andrews et al. 1987; Shuckburgh et al. 2001):

$$
\bar{q}_{y}=\beta-\bar{u}_{y y}-\frac{f^{2}}{\rho_{0}}\left(\frac{\rho_{0}}{N^{2}} \bar{u}_{z}\right)_{z}
$$

Here the overbars denote zonal averages while the subscripts denote partial derivatives. The parameter $\mathrm{N}$ refers to the buoyancy frequency, $\rho_{0}$ is the basic state density, $\bar{u}$ is the zonal-mean zonal wind, $f$ is coriolis parameter ( $f=2 \Omega \sin \varphi ; \Omega=7.292 \times 10^{-5} \operatorname{Rads}^{-1} ; \varphi$ is the latitude), and $\beta$ is the Rossby parameter $\left(\beta=\frac{2 \Omega \cos \varphi}{a} ; a\right.$ is the mean Earth radius). The first two terms in this expression represent the barotropic instability while the last term indicates the baroclinic instability. A necessary condition for instability of the mean flow is that the basic northward quasi-geostrophic potential vorticity gradient must change sign somewhere in the flow domain (Andrews et al. 1987). The mean flow instability might excite the 10-day waves. In such case, the waves might extract energy from the mean flow and get amplified. The negative values of $\bar{q}_{y}$ (referring to presence of instability) are shown with the colored contours in the top row in Fig. 5. Because of validity limitations of the quasi-geostrophic approximation near the equator and surface, and numerical singularities near the poles, the $\bar{q}_{y}$ values at latitudes less than $\pm 15^{\circ}$, latitudes greater than $\pm 80^{\circ}$, and altitude below $1 \mathrm{~km}$ are not shown in Fig. 5 .

As the second step, the basic northward potential vorticity gradient is used to analyze the refractive index squared by using the expression defined as follows (Andrews et al. 1987):

$$
n^{2}=\frac{\bar{q}_{y}}{\bar{u}-c}-\frac{f^{2}}{4 H^{2} N^{2}}-\frac{s^{2}}{a^{2} \cos ^{2} \varphi} .
$$

Here, $\bar{u}, f, N, a$, and $\varphi$ are the same quantities as those in Eq. (2). In addition, $H$ is the scale height, $s$ is the zonal wavenumber, and $\mathrm{c}$ is the phase velocity. The 10-day waves could propagate meridionally and/or vertically in the regions where $n^{2}>0$ while be evanescent or reflected from the regions where $n^{2}<0$. The negative values of $n^{2}$ (indicating evanescence regions) are shaded with red color in the second row in Fig. 5.

The Eliassen-Palm (EP) flux and its divergence are analyzed by using the zonal Transformed Eulerian-Mean momentum equation under quasi-geostrophic approximation in spherical log (pressure) coordinates (Edmon et al. 1980; Andrew et al. 1987; Andrew 1987; Fritts et al. 1999) applying the formula below: 

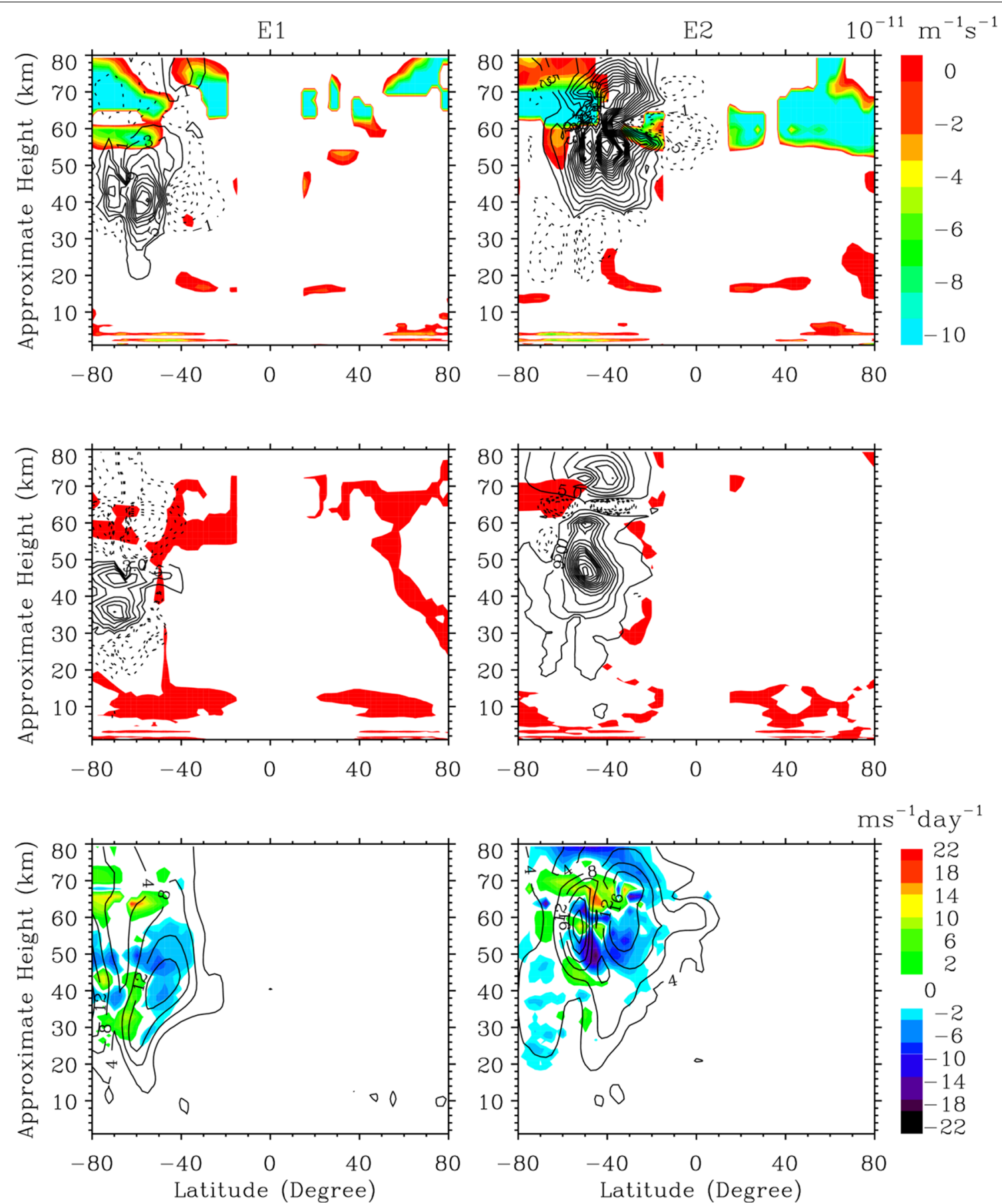

Fig. 5 Latitude-altitude sections of the potential vorticity gradient (the top row), the refractive index squared (the middle row) and the divergence of the EP flux (the bottom row) for E1 wave over September 11-30 (the first column), and E2 wave over June 2-21 (the second column) in 2013, respectively. Regions with negative refractive index squared are shaded in red, while regions with negative potential vorticity gradient and regions with significant EP flux divergence or convergence are represented by colored contours. The black contours denote EPX (the top row), EPZ (the middle row), and the zonal wind amplitudes (the bottom row) of these two 10-day waves. Solid and dotted black contours denote the northward and southward directions for EPX in the top row, and the upward and downward directions for EPZ in the second row 


$$
\bar{u}_{t}+\bar{v}^{*}\left[(a \cos \phi)^{-1}(\bar{u} \cos \phi)_{\phi}-f\right]+\overline{\mathrm{w}}^{*} \bar{u}_{z}=\left(\rho_{0} a \cos \phi\right)^{-1} \nabla \cdot \mathbf{F}
$$

The meridional and vertical components of the EP flux (F) are defined, respectively, as,

$$
F^{(\varphi)}=\rho_{0} a \cos \varphi\left(\bar{u}_{z} \overline{v^{\prime} \theta^{\prime}} / \bar{\theta}_{z}-\overline{u^{\prime} v^{\prime}}\right)
$$

and

$$
F^{(z)}=\rho_{0} a \cos \varphi\left\{\left[f-(a \cos \varphi)^{-1}(\bar{u} \cos \varphi)_{\varphi}\right] \overline{v^{\prime} \theta^{\prime}} / \bar{\theta}_{z}-\overline{u^{\prime} w^{\prime}}\right\},
$$

where primes denote perturbation quantities (deviations from the zonal averages); $\bar{v}^{*}$ and $\overline{\mathrm{w}}^{*}$ are the meridional and vertical components of the residual mean meridional circulation; $u, v$, and $w$ are, respectively, the zonal, meridional and vertical winds; and $\theta$ is the potential temperature. The zonal force per unit mass acting on the mean state is defined as $D_{F}=\left(\rho_{0} a \cos \phi\right)^{-1} \nabla \cdot \mathbf{F}$. Since the term proportional to the $\overline{v^{\prime} \theta^{\prime}} / \bar{\theta}_{z}$ dominates the vertical EP flux component, the term proportional to $\overline{u^{\prime} w^{\prime}}$ is omitted in the calculations. The meridional and vertical components of the EP flux refer to a generalization of the group velocity concept so that their cross-sections can be used to visualize the flow of wave energy density (Andrews 1987; Riggin et al. 2006). Regions of positive (negative) EP flux divergence are sources (sinks) of wave energy, where the wave is amplified (dissipated). Because of the density factors in Eqs. (5) and (6), the components of the EP flux have a large dynamic range. For a better height representation, the meridional and vertical components of the EP flux are scaled by density, which are $\frac{F^{(\varphi)}}{\rho_{0}}$ and $\frac{F^{(z)}}{\rho_{0}}$. We refer to these scaled components as EPY and EPZ, and display them with the black contours in the first and second rows in Fig. 5. Regions of significant positive and negative EP flux divergence indicate dramatic wave amplification and dissipation, which are shown with colored contours in the bottom row in Fig. 5. The zonal wind amplitudes are also displayed with black contours in this row.

Over September 11-30 in 2013, E1 wave had significant zonal wind amplitudes at mid- and high-latitudes in the SH. The largest amplitude peak of $18.9 \mathrm{~ms}^{-1}$ was located at $47.5^{\circ} \mathrm{S}$ and $\sim 42 \mathrm{~km}$ while the second peak of $17.5 \mathrm{~ms}^{-1}$ was at $80^{\circ} \mathrm{S}$ and $\sim 37 \mathrm{~km}$. Its refractive index squared showed that, evanescence regions below $4 \mathrm{~km}$ and in $8-18 \mathrm{~km}$ almost covered all the latitudes and it was not favorable for the upward wave propagation in the troposphere. E1 wave showed downward propagation in the mid-latitudes from $\sim 18$ to $\sim 40 \mathrm{~km}$ and in the high latitudes from $\sim 18$ to $\sim 30 \mathrm{~km}$, which proved that the E1 wave peak at $\sim 42 \mathrm{~km}$ did not come from the upward propagation wave from the troposphere. At $\sim 40 \mathrm{~km}$ (midlatitudes) and $\sim 30 \mathrm{~km}$ (high latitudes), the upward and downward propagations indicates that there is an in situ source for E1 wave. However, this source is not related to the mean flow instability. Large evanescence regions at $\sim 60 \mathrm{~km}$ block the upward propagation of the excited E1 wave in the stratosphere, so that the E1 wave peaks at $\sim 42 \mathrm{~km}$ are formed. The southward propagating E1 wave at mid-latitudes might be the reflected wave from the vertical evanescence region located at about $50^{\circ} \mathrm{S}$. In the unstable region above $\sim 54 \mathrm{~km}$ at high latitudes, E1 wave displays downward propagation. This implies that the mean flow instability likely plays an important role on the excitation of E1 wave. And, the EP flux divergence indeed shows large positive values of $21.4 \mathrm{~ms}^{-1}$ day there. E1 wave can also exert strong zonal forcing on the mean flow at mid-and high-latitudes above $\sim 24 \mathrm{~km}$, but the EP flux convergence is clearly weaker than the divergence. The strongest convergence of $-8.4 \mathrm{~ms}^{-1}$ day $^{-1}$ is located at $50.0^{\circ} \mathrm{S}$ and $\sim 48 \mathrm{~km}$.

Over June 2-21 in 2013, E2 wave had significant zonal wind amplitudes at mid-latitudes in the SH. The largest zonal wind amplitude peak of $26.9 \mathrm{~ms}^{-1}$ is located at $52.5^{\circ}$ $\mathrm{S}$ and $\sim 58 \mathrm{~km}$ while the second peak of $18.9 \mathrm{~ms}^{-1}$ is positioned at $35^{\circ} \mathrm{S}$ and $\sim 58 \mathrm{~km}$. Its refractive index squared indicates that E2 wave can propagate freely at mid-latitudes at about 4-15 km, and at mid- and high-latitudes at about $15-62 \mathrm{~km}$ where the wave energy mainly propagates upward. A roughly vertical evanescence region is present at around $20^{\circ} \mathrm{S}$. For this reason, it is believed that E2 wave in the stratosphere and mesosphere mainly originates from the one in the troposphere in the same hemisphere (since the evanescence regions at low latitudes can prohibit the cross equatorial propagation of wave) by upward propagation. Near $40.0^{\circ} \mathrm{S}$ and $\sim 68 \mathrm{~km}$, the mean flow instability is present, and the wave propagates upward above this height and downward below this height. It implies that the in situ mean flow instability causes E2 wave. The positive EP flux divergence around this location is strong as of $20.0 \mathrm{~ms}^{-1}$ day $^{-1}$, further verifying the presence of E2 wave source. In general, E2 wave can exert strong zonal forcing on the mean flow, especially in the altitudes above $40 \mathrm{~km}$, where it has large amplitudes. Not the divergence but the convergence is also very intensive as of $-19.7 \mathrm{~ms}^{-1}$ day $^{-1}$ at $45.0^{\circ} \mathrm{S}$ and $\sim 50 \mathrm{~km}$. Compared with E1 wave, it seems that the dramatic forcing from $\mathrm{E} 2$ wave is located in an equatorward region.

\section{Summary and discussion}

A least-squares harmonic fitting procedure is applied to extract the 10-day waves with zonal wavenumbers varying from -6 to 6 in the recent 12 years from 2007 to 2018 
from MERRA-2 data. Climatology study reveals the primary characteristics of the 10-day waves with various zonal wave numbers from surface to the middle mesosphere on the basis of the large amplitude occurrence rate by checking all the fitting amplitudes.

It is determined that the dominant propagating 10-day waves from surface to the middle mesosphere are W1, E1, and E2 waves. Although the active regions for these three waves are all at mid- and high-latitudes above the troposphere, there are still significant differences among them. Large amplitudes are present mainly in the $\mathrm{NH}$ for W1 wave, equally in both hemispheres for E1 wave, and mainly in the SH for E2 wave, respectively.

In terms of height distribution, large wind amplitudes are mainly located just above the stratopause in the $\mathrm{NH}$, just below the stratopause in both hemispheres, and around the middle stratosphere in the $\mathrm{SH}$ for W1, E1, and E2 waves, respectively. Each wave presents only one height center in the stratosphere and mesosphere in the zonal and meridional winds. The heights of these centers for W1, E1 and E2 waves decrease in turn. In the temperature, large amplitudes have two centers in the stratosphere and mesosphere for W1 and E1 waves while three centers for E2 wave. W1 wave is strong around $\sim 58 \mathrm{~km}$, and decays near the mesopause, which agrees well with previous work (Hirooka 2000).

All these three waves display significant month-tomonth variations. W1 wave is active in the $\mathrm{NH}$ from December to March while E2 in the SH from June to October. On the other hand, E1 wave is active in the $\mathrm{SH}$ from August to October and also in the NH from December to February. W1 wave is strong during winter and spring months while weak during summer months, which is consistent with previous work (Forbes and Zhang 2015).

For E1 and E2 waves, case study is performed on the two 20-day time segments, i.e., September $11-30$ and June 2-21 in 2013, respectively, when intense wave activity is present. The calculation results of Potential vorticity gradient, refractive index squared, Eliassen-Palm flux and its divergence could explain the formation of the latitude-height structures of these two eastward waves and provide evidence for the likely wave origins. The prominent 10-day waves in the stratosphere and mesosphere appear only under the condition that they can freely travel considerable distance in the vertical direction. Their meridional propagation can be limited by the vertical evanescence regions.

Our case study also suggests that the mean flow instability forcing mechanism indeed takes place in the mesosphere. Both eastward-propagating 10-day waves in the stratosphere and mesosphere partly originate from the downward-propagating wave excited in the mesosphere by the mean flow instability, which conforms well with previous work (Hartmann 1979, 1983; Mechoso and Hartmann 1982; Palo et al. 2005). Except that, the E2 wave in the stratosphere and mesosphere is also a result of the upward-propagating waves from the troposphere while part of the E1 wave in the stratosphere and mesosphere come from in situ excited wave in the stratosphere which is independent of the mean flow instability. In a word, the excitation mechanism for the dominant eastward-traveling 10-day waves is complex and further investigation is needed. The calculated EP flux divergence reveal that the two eastward waves can exert strong zonal forcing on the mean flow at mid- and high-latitudes above the troposphere in the specific periods. Compared with E2 wave, the dramatic forcing from E1 wave is located in poleward regions.

\section{Abbreviations}

PWs: Planetary waves; MLT: Mesosphere and lower thermosphere; TLS: Troposphere and lower stratosphere; SABER: The Sounding of the Atmosphere using Broadband Emission Radiometry; MERRA-2: The Modern-Era Retrospective Analysis for Research and Applications version 2; $\mathrm{NH}$ : Northern hemisphere; $\mathrm{SH}$ : Southern hemisphere; EP: Eliassen-Palm.

\section{Acknowledgements}

We thank the Goddard Earth Sciences Data and Information Services Center (GES DISC) for the dissemination of MERRA-2 data.

\section{Authors' contributions}

$\mathrm{CH}$ conceived and coordinated this study, and wrote the first draft of the paper. WL carried out the reanalysis data processing and also assisted in manuscript preparation. SZ performed analyses related to the present study, and interpreted the results. GC, KH and YG contributed to the scientific interpretation. All authors read and approved the final manuscript.

\section{Funding}

The present work is jointly supported by the National Natural Science Foundation of China under Grant Numbers 41874178, 42074182 and 41531070, and the Meridian Space Weather Monitoring Project.

Availability of data and materials

The MERRA-2 data used and analyzed in the present study are available from the websites of https://disc.gsfc.nasa.gov.

\section{Declarations}

\section{Competing interests}

The authors declare that they have no competing interests.

\section{Author details}

${ }^{1}$ School of Electronic Information, Wuhan University, Wuhan, Hubei, China. ${ }^{2}$ Key Laboratory of Geospace Environment and Geodesy, Ministry of Education, Wuhan, Hubei, China.

Received: 16 September 2020 Accepted: 26 March 2021

Published online: 09 April 2021

\section{References}

Andrews DG (1987) On the interpretation of the Eliassen-Palm flux divergence. Q J R Meteorol Soc 113:323-338 
Andrews DG, Holton JR, Leovy CB (1987) Middle atmosphere dynamics. Academic Press Inc, Cambridge, p 489

Charney JG, Drazin PG (1961) Propagation of planetary-scale disturbances from the lower into the upper atmosphere. J Geophys Res 66:83-109

Chun H-Y, Kim Y-H (2008) Secondary waves generated by breaking of convective gravity waves in the mesosphere and their influence in the wave momentum flux. J Geophys Res 113:D23107. https://doi.org/10.1029/ 2008JD009792

Edmon HJ, Hoskins BJ, McIntyre ME (1980) Eliassen-Palm cross sections for the troposphere. J Atmos Sci 37:2600-2616

Fritts DC, Isler JR, Lieberman RS, Burrage MD, Marsh DR, Nakamura N et al (1999) Two-day wave structure and mean flow interactions observed by radar and High Resolution Doppler Imager. J Geophys Res 104:3953-3969

Forbes JM, Hagan ME, Miyahara S, Vial F, Manson AH, Meek CE et al (1995) Quasi 16-day oscillation in the mesosphere and lower thermosphere. J Geophys Res 100:9149-9163

Forbes JM, Zhang X (2015) Quasi-10-day wave in the atmosphere. J Geophys Res Atmos 120:11079-11089. https://doi.org/10.1002/2015JD023327

Gelaro R, McCarty W, Suárez MJ, Todling R, Molod A, Takacs L et al (2017) The modern-era retrospective analysis for research and applications, Version 2 (MERRA-2). J Climate 30:5419-5454. https://doi.org/10.1175/ JCLI-D-16-0758.1

Gong Y, Li C, Ma Z, Zhang S, Zhou Q, Huang C et al (2018) Study of the quasi5-day wave in the MLT region by a meteor radar chain. J Geophys Res Atmos 123:9474-9487. https://doi.org/10.1029/2018JD029355

Grieger N, Schmitz G (1982) The structure of planetary waves up to the lower mesosphere based on data analyses and model calculations. J Geophys Res 87:11255-11264

Hartmann DL (1979) Baroclinic instability of realistic zonal-mean states to planetary waves. J Atmos Sci 36:2336-2349

Hartmann DL (1983) Baroclinic instability of the polar night jet stream. J Atmos Sci 40:1141-1154

Hirooka T (1986) Influence of normal mode Rossby waves on the mean field: Influence with quasi-stationary waves. J Atmos Sci 43:2088-2097

Hirooka T (2000) Normal mode Rossby waves as revealed by UARS/ISAMS observations. J Atmos Sci 57:1277-1285. https://doi.org/10.1175/15200469(2000)057\%3c1277:NMRWAR\%3e2.0.CO;2

Hirooka T, Hirota I (1985) Normal mode Rossby waves observed in the upper stratosphere. Part II: Second antisymmetric and symmetric modes of zonal wavenumbers 1 and 2. J Atmos Sci 42:536-548

Holton JR (1984) The generation of mesospheric planetary waves by zonally asymmetric gravity wave breaking. J Atmos Sci 41:3427-3430

Huang CM, Zhang SD, Yi F (2009) Intensive radiosonde observations of the diurnal tide and planetary waves in the lower atmosphere over Yichang $\left(111^{\circ} 18^{\prime} \mathrm{E}, 30^{\circ} 42^{\prime} \mathrm{N}\right)$, China. Ann Geophys 27:1079-1095

Huang C, Zhang S, Zhou Q, Yi F, Huang K, Gong Y et al (2015) WHU VHF radar observations of the diurnal tide and its variability in the lower atmosphere over Chongyang $\left(114.14^{\circ} \mathrm{E}, 29.53^{\circ} \mathrm{N}\right)$. China Ann Geophys 33:865-874

Huang C, Zhang S, Chen G, Zhang SY, Huang K (2017) Planetary wave characteristics in the lower atmosphere over Xianghe $\left(117.00^{\circ} \mathrm{E}, 39.77^{\circ} \mathrm{N}\right)$, China, revealed by the Beijing MST radar and MERRA data. J Geophys Res Atmos 122:9745-9758. https://doi.org/10.1002/2017JD027029

Luo Y, Manson AH, Meek CE (2000) The 16-day oscillations in the mesosphere and lower thermosphere at Saskatoon $\left(52^{\circ} \mathrm{N}, 107^{\circ} \mathrm{W}\right), 1980-1996 . \mathrm{J}$ Geophys Res 105:2125-2138

Madden RA (2007) Large-scale, free Rossby waves in the atmosphere-An update. Tellus 59A:571-590

McDonald AJ, Hibbins RE, Jarvis MJ (2011) Properties of the quasi 16 day wave derived from EOS MLS observations. J Geophys Res 116:D06112. https:// doi.org/10.1029/2010JD014719

Mechoso CR, Hartman DL (1982) An observational study of traveling planetary waves in the Southern Hemisphere. J Atmos Sci 39:1921-1935
Meyer CK, Forbes JM (1997) A 6.5-day westward propagating planetary wave: origin and characteristics. J Geophys Res 102:26173-26178. https://doi. org/10.1029/97JD01464

Moudden Y, Forbes JM (2014) Quasi-two-day wave structure, inter-annual variability, and tidal interactions during the 2002-2011 decade. J Geophys Res Atmos 119:2241-2260. https://doi.org/10.1002/2013JD020563

Osprey SM, Lawrence BN (2001) A possible mechanism for in situ forcing of planetary waves in the summer extratropical mesosphere. Geophys Res Lett 28:1183-1186

Palo SE, Forbes JM, Zhang X, Russell JM, Mertens CJ, Mlynczak MG et al (2005) Planetary wave coupling from the stratosphere to the thermosphere during the 2002 Southern Hemisphere pre-stratwarm period. Geophys Res Lett 32:L23809

Pancheva DV, Mukhtarov PJ, Andonov BA (2007) Zonally symmetric oscillations in the Northern Hemisphere stratosphere during the winter of 2003-2004. Geophys Res Lett 34:L04807. https://doi.org/10.1029/2006G L028666

Pancheva D, Mukhtarov P, Mitchell NJ, Merzlyakov E, Smith AK, Andonov B et al (2008) Planetary waves in coupling the stratosphere and mesosphere during the major stratospheric warming in 2003/2004. J Geophys Res 113:D12105. https://doi.org/10.1029/2007JD009011

Pancheva D, Mukhtarov P, Siskind DE, Smith AK (2016) Global distribution and variability of quasi 2 day waves based on the NOGAPS-ALPHA reanalysis model. J Geophys Res Space Physics 121:11422-11449. https://doi.org/ 10.1002/2016JA023381

Pancheva D, Mukhtarov P, Siskind DE (2018) The quasi-6-day waves in NOGAPS-ALPHA forecast model and their climatology in MLS/Aura measurements (2005-2014). J Atmos and Solar-Terr Phys 181:19-37

Rienecker MM, Suarez MJ, Gelaro R, Todling R, Bacmeister J, Liu E et al (2011) MERRA: NASA's modern-era retrospective analysis for research and applications. J Climate 24:3624-3648. https://doi.org/10.1175/ Jcli-D-11-00015.1

Riggin DM, Liu H-L, Lieberman RS, Roble RG, Russell JM III, Mertens CJ et al (2006) Observations of the 5-day wave in the mesosphere and lower thermosphere modern-era retrospective analysis for research and applications. J Atmos and Solar-Terr Phys 68:323-339

Salby ML (1981) Rossby normal modes in nonuniform background configurations. Part II: Equinox and solstice conditions. J Atmos Sci 38:1827-1840

Salby ML (1984) Survey of planetary-scale traveling waves: The state of theory and observations. Rev Geophys 22(2):209-236

Sassi F, Garcia RR, Hoppel KW (2012) Large-scale Rossby normal modes during some recent Northern Hemisphere winters. J Atmos Sci 69:820-839

Smith AK (1996) Longitudinal variations in mesospheric winds: evidence for gravity wave filtering by Planetary Waves. J Atmos Sci 53:1156-1173

Shuckburgh E, Norton W, Iwi A, Haynes P (2001) Influence of the quasi-biennial oscillation on isentropic transport and mixing in the tropics and subtropics. J Geophys Res 106:14327-14337. https://doi.org/10.1029/2000J D900664

Vincent RA (1990) Planetary and gravity waves in the mesosphere and lower thermosphere. Adv Space Res 10:93-101

Williams CR, Avery SK (1992) Analysis of long-period waves using the mesosphere-stratosphere-troposphere radar at poker flats, Alaska. J Geophys Res 97:20855-20861

Yue J, Liu H-L, Chang LC (2012) Numerical investigation of the quasi 2 day wave in the mesosphere and lower thermosphere. J Geophys Res 117:D05111. https://doi.org/10.1029/2011JD016574

\section{Publisher's Note}

Springer Nature remains neutral with regard to jurisdictional claims in published maps and institutional affiliations. 